\title{
Gap junction proteins and their role in spinal cord injury
}

\section{Ryan S. Tonkin ${ }^{1}$, Yilin Mao ${ }^{2}$, Simon J. O'Carroll ${ }^{3}$, Louise F. B. Nicholson ${ }^{3}$, Colin R. Green ${ }^{4}$, Catherine A. Gorrie ${ }^{2}$ and Gila Moalem-Taylor ${ }^{*}$}

${ }^{1}$ School of Medical Sciences, Faculty of Medicine, University of New South Wales, Sydney, NSW, Australia

${ }^{2}$ School of Medical and Molecular Bioscience, Faculty of Science, University of Technology, Sydney, NSW, Australia

${ }^{3}$ Department of Anatomy with Radiology and Centre for Brain Research, Faculty of Medical and Health Sciences, University of Auckland, Auckland, New Zealand

${ }^{4}$ Department of Ophthalmology, Faculty of Medical and Health Sciences, University of Auckland, Auckland, New Zealand

\section{Edited by:}

Nicola Maggio, The Chaim Sheba

Medical Center, Israel

Reviewed by:

Sheriar Hormuzdi, University of

Dundee, UK

Michele Papa, Seconda Università degli Studi di Napoli, Italy

Ping Liu, University of Connecticut Health Center, USA

\section{*Correspondence:}

Gila Moalem-Taylor, School of Medical Sciences, Faculty of Medicine,

University of New South Wales,

Wallace Wurth Building East, Level 3,

Room 327, Sydney, NSW 2052,

Australia

e-mail: gila@unsw.edu.au
Gap junctions are specialized intercellular communication channels that are formed by two hexameric connexin hemichannels, one provided by each of the two adjacent cells. Gap junctions and hemichannels play an important role in regulating cellular metabolism, signaling, and functions in both normal and pathological conditions. Following spinal cord injury (SCl), there is damage and disturbance to the neuronal elements of the spinal cord including severing of axon tracts and rapid cell death. The initial mechanical disruption is followed by multiple secondary cascades that cause further tissue loss and dysfunction. Recent studies have implicated connexin proteins as playing a critical role in the secondary phase of $\mathrm{SCl}$ by propagating death signals through extensive glial networks. In this review, we bring together past and current studies to outline the distribution, changes and roles of various connexins found in neurons and glial cells, before and in response to $\mathrm{SCl}$. We discuss the contribution of pathologically activated connexin proteins, in particular connexin 43 , to functional recovery and neuropathic pain, as well as providing an update on potential connexin specific pharmacological agents to treat $\mathrm{SCl}$.

\section{Keywords: spinal cord injury, gap junctions, hemichannels, connexins, neuropathic pain}

\section{INTRODUCTION}

Gap junctions are specialized intercellular connections that allow direct electrical and metabolic communication between two adjacent cells; they are therefore vital to many physiological processes. By controlling the movement of amino acids, second messengers, ions, and other metabolites, gap junctions are able to coordinate cellular signaling and propagate electrical signals (Hertzberg etal., 1981; Söhl etal., 2005). In vertebrates, gap junctions are formed by two hemichannels (or connexons), one provided by each of two cells. Each hemichannel consists of six oligomerized connexin proteins (abbreviated as $\mathrm{Cx}$ ), which can be either homomeric or heteromeric (two or more different connexins in a connexon) and form homotypic or heterotypic (different connexons) gap junction channels (Orthmann-Murphy et al., 2008). Connexins are named according to their estimated molecular weights and have been shown to be expressed in almost all mammalian tissues (Söhl and Willecke, 2003; Söhl et al., 2005). The structure of these connexin proteins is described in Figures 1A,B.

While two hemichannels form gap junctions that directly connect the interiors of two adjacent cells without facing the external milieu, increasing evidence indicates that unopposed hemichannels can open to the extracellular space in response to various physiological and pathological stimuli (Bennett etal., 2003). In such contexts, connexin hemichannels may become activated in response to various intracellular signals including changes in $\mathrm{pH}$, phosphorylation status, extracellular signals such as a low $\mathrm{Ca}^{2+}$ environment, and mechanical, oxidative, metabolic, and ischemic stresses (Contreras etal., 2002; Retamal etal., 2007; Shintani-Ishida etal., 2007). Indeed, studies using dye uptake measurements, recording of hemichannel activity in single cells, and pharmacological blockade of hemichannels in transfected cells have demonstrated that connexins form unopposed hemichannels that can open to the exterior (Contreras et al., 2003; Li et al., 2004). Opened hemichannels lead to the release of molecules such as potassium, ATP, and glutamate into the extracellular space, that under physiological conditions may modulate neuronal activity and under pathological conditions may ultimately induce cell death (Evans et al., 2006; Chever et al., 2014). In addition, gap junctional communication can be likewise regulated by numerous signals, such as connexin phosphorylation and post-translational modification at the C-terminal tail, intracellular acidification, intracellular $\mathrm{pH}$, and inflammatory mediators (Lampe and Lau, 2000; Faustmann etal., 2003; Hinkerohe et al., 2005; Haghikia et al., 2008; Iyyathurai et al., 2013).

In this review, we discuss the expression and function of gap junction/hemichannel proteins in the intact and injured spinal cord, their role in neuropathic pain following spinal cord injury (SCI), and the therapeutic implications.

\section{DISTRIBUTION AND ROLES OF CONNEXINS IN THE SPINAL CORD}

In the normal functioning central nervous system (CNS), gap junctions are formed by fully docked connexons, which play a vital physiological role in the development of communicative pathways in glial and neuronal cells. Studies examining the distribution and functional role of connexins in the spinal cord indicate that connexin-formed gap junctions undergo cell-tocell coupling between neurons, adjacent astrocytes, and astrocytes/oligodendrocytes (Figure 1C; Chang et al., 1999; Chang and 


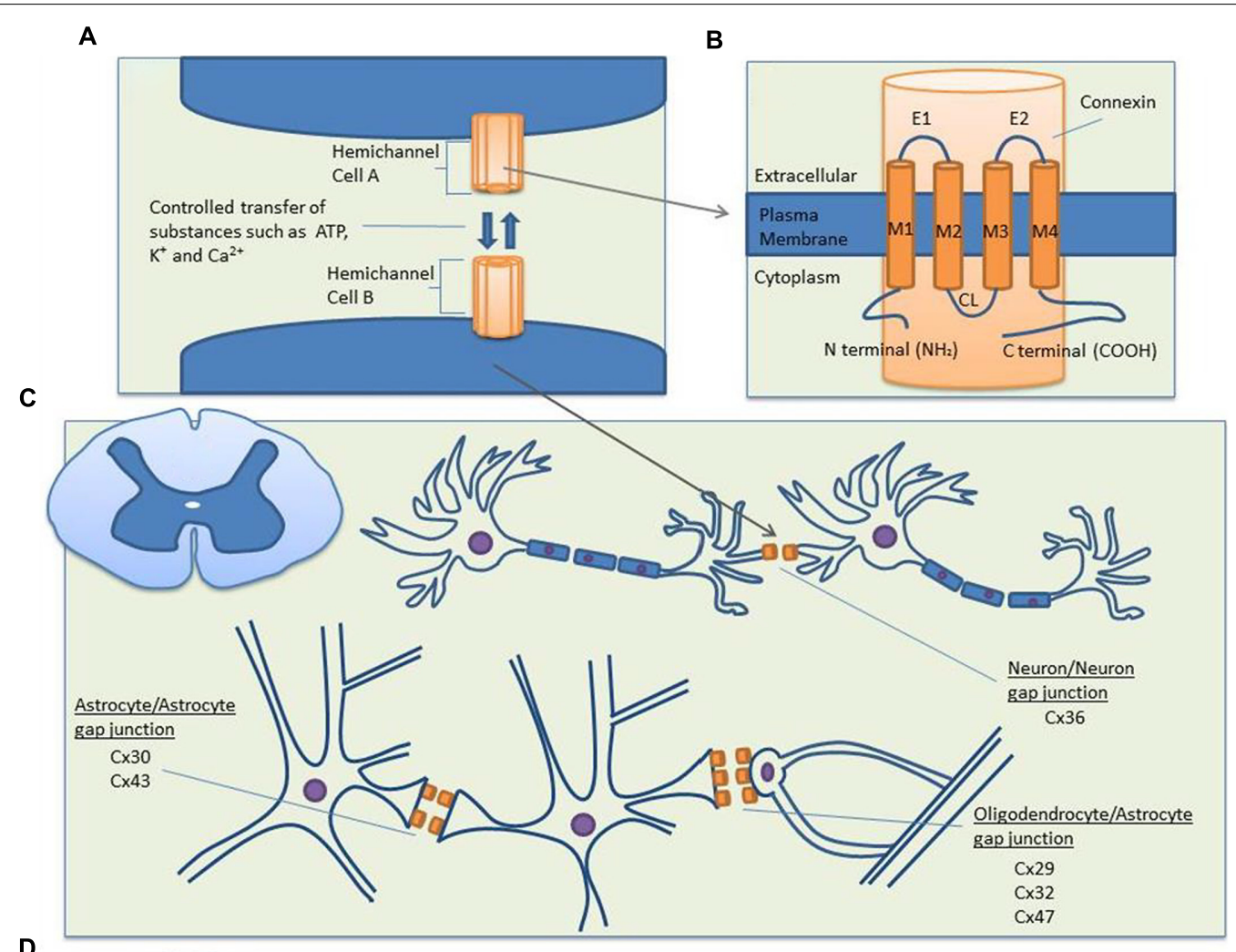

D

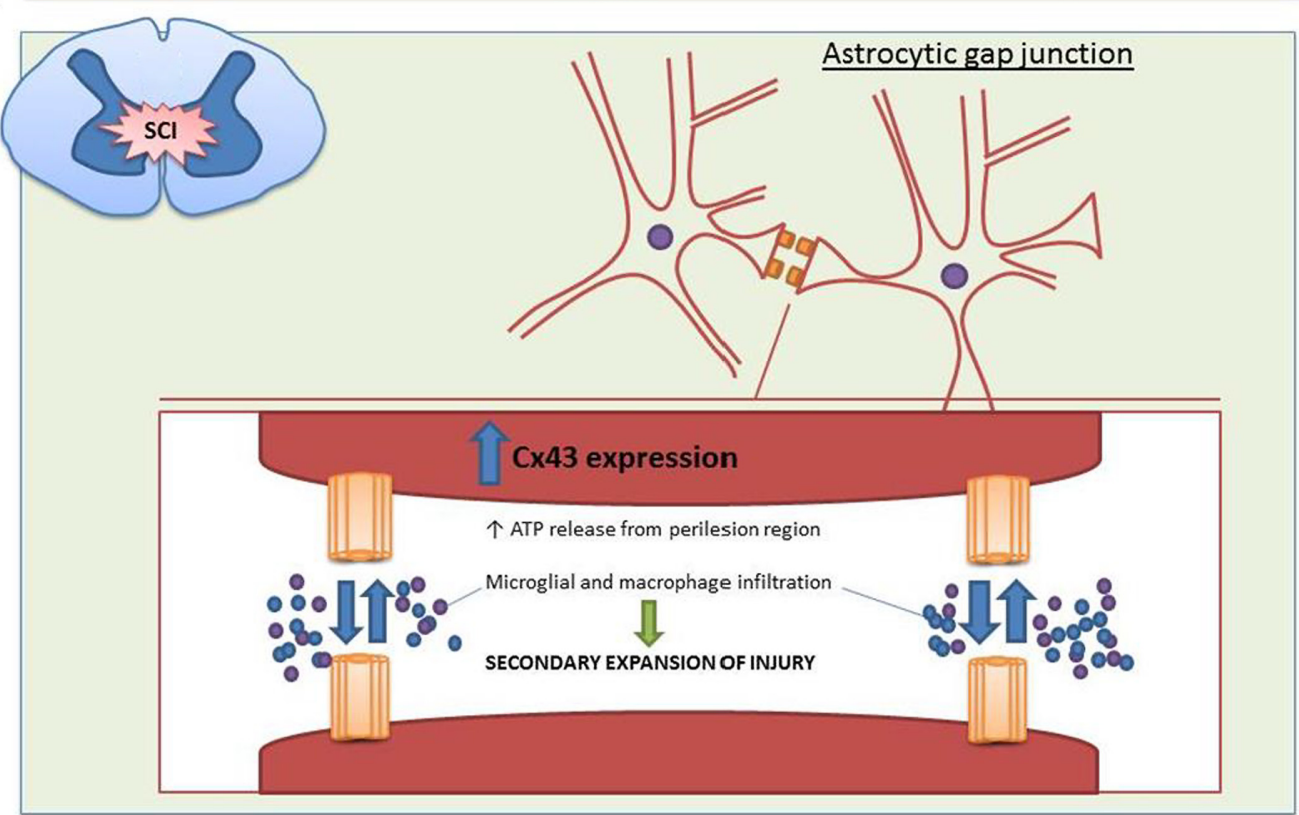

FIGURE 1 | Structure and distribution of the main connexin proteins in the spinal cord before and after $\mathbf{S C l}$. (A) Gap junction channels are produced by the conjoining of two hemichannels, with one hemichannel provided by each cell. Compared to the closed state $(\sim 1.8 \mathrm{~nm})$, opened channels $(\sim 2.5 \mathrm{~nm})$ allow the transfer of substances less than $1 \mathrm{kDa}$ between the cytoplasms of two cells, including nutrients, metabolites, $\mathrm{K}^{+}$, ATP, CAMP, and $\mathrm{Ca}^{2+}$. (B) Each hemichannel is composed of six individual connexin proteins, which contain four transmembrane domains. The cytoplasmic loop $(\mathrm{CL})$, amino $(\mathrm{N})$, and carboxy $(\mathrm{C})$ terminals are located on the cytoplasmic side, with multiple regulatory phosphorylation sites located on the $C$ termini. There are two extracellular loops (E1 and E2) which contain three highly conserved cysteine bonds that play a role in the docking of hemichannels from opposing cells via intramolecular cysteine/cysteine bonds. (C) In the spinal cord, there is a large distribution of connexins. Neuron/neuron gap junctions contain $\mathrm{C} \times 36$, astrocyte/astrocyte junctions contain $\mathrm{C} \times 30$ and $\mathrm{C} \times 43$ and oligodendrocyte/astrocyte gap junctions contain $\mathrm{C} \times 29, \mathrm{C} \times 32$, and $\mathrm{C} \times 47$ with the major heterotypic channels composed of $\mathrm{C} \times 43-\mathrm{C} \times 47$ and $\mathrm{C} \times 30-\mathrm{C} \times 32$. (D) Following $\mathrm{SCl}, \mathrm{C} \times 43$ expression is increased in astrocytes. This causes an uncontrolled release of the small molecule ATP from the perilesion region. ATP release leads to the activation of a destructive inflammatory response including recruitment of microglia and macrophages to the site of injury, which causes an increased secondary expansion of the lesion. 
Balice-Gordon, 2000; Rash et al., 2000; Kleopa et al., 2004; Lee et al., 2005; Orthmann-Murphy et al., 2008).

In neurons, gap junctional coupling is widespread during neural development but declines during the first postnatal week. Gap junctional communication in the developing spinal cord is vital in synchronizing neuronal cells and providing electrical synapses, which act as support frameworks for neuronal activity prior to the development of chemical synapses (Chang et al., 1999; Kiehn et al., 2000; Altevogt et al., 2002; Kiehn and Tresch, 2002; Wilson et al., 2007). Developing motor neurons in the spinal cord express Cx36, Cx37, Cx40, Cx43, and Cx45 mRNA. While electrical and dye coupling decrease at about 1 week postnatal along with $\mathrm{Cx} 40$ and Cx45 expression, the remaining connexins persist into adulthood (Chang et al., 1999; Chang and Balice-Gordon, 2000). Although earlier studies by Chang et al. (1999) were unable to demonstrate Cx36 and Cx37 protein by immunohistochemistry, more recent studies using sensitive techniques such as in situ hybridization and freeze-fracture replica immunogold labeling (FRIL) were able to detect Cx36 mRNA and protein, respectively. Cx36 mRNA was found to be confined to the cytoplasm of spinal neurons but was more strongly expressed in developing neurons compared to adult rodent spinal cord neurons (Lee et al., 2005). A recent study using transgenic mice expressing Cx36 protein tagged with enhanced green florescent protein, showed a substantial number of florescent clusters in the white matter of the spinal cord providing further evidence for the presence of $\mathrm{Cx} 36$ in the adult spinal cord (Meyer et al., 2014). Using FRIL, there was no evidence for the presence of $\mathrm{Cx} 26$ in neuronal gap junctions in the perinatal or adult spinal cord (Nagy et al., 2001). While it may be possible that there are as yet unidentified connexins in neuronal gap junctions, more recent studies have implicated Cx36 as the major connexin in mediating electrical synapses in neurons of the spinal cord (Bautista et al., 2014). In adults, neuronal gap junction channels are proposed to contribute to a number of different cognitive processes such as perception, memory, and learning (Buzsáki and Chrobak, 1995; Fricker and Miles, 2001). These gap junction channels are able to sharpen neuronal activity by enhancing the efficacy and precision of synchronous oscillatory activity in neurons (Hormuzdi et al., 2004; Gibson et al., 2005).

In astrocytes, Cx43 and Cx30 are abundantly expressed and are found densely populated around the ependymal and leptomeningeal membranes of the neonatal rodent spinal cord, roughly 4 weeks postnatal (Dahl et al., 1996; Kunzelmann et al., 1999; Lee et al., 2005). It has also been shown using FRIL analysis that leptomeningeal cells in the rats midthoracic spinal cord are highly labeled for $\mathrm{Cx} 26$, and that most astrocyte gap junctions in the parenchyma of adult spinal cord are labeled for both Cx26 and Cx30 or Cx26 alone (Nagy et al., 2001). However, recent evidence has suggested a degree of uncertainty over the presence of Cx26 in astrocytes. In postnatal day 4 rats, regions of spinal leptomeningeal cells were found to be largely unlabeled for Cx26 using immunohistochemistry (Nagy et al., 2001). While it is possible that this result reflects the low labeling efficiency for $\mathrm{Cx} 26$ at postnatal day 4 , recent evidence has shown that the $\mathrm{Cx} 26$ antibody may cross-react with Cx30 (Altevogt and Paul, 2004; Orthmann-Murphy et al., 2008). Furthermore, a study using mice with genetically altered
Cx26 allele that allows visualization of Cx26 expression has shown that in both the embryonic and mature CNS, Cx26 was restricted to meningeal cells and could not be detected by either neurons or glia, including astrocytes (Filippov et al., 2003). The importance of these astrocytic connexins to normal physiology appears to be linked to their ability to regulate synaptic function. For example, blockade and deletion of astrocytic $\mathrm{Cx} 43$ has been shown to impair fear memory consolidation and cause alterations in synaptic transmission and plasticity in rats (Pannasch et al., 2011; Stehberg et al., 2012).

There are limited studies on microglial connexins in the spinal cord. A study by Lee et al. (2005) using immunohistochemistry and triple labeling of $\mathrm{Cx} 43$, glial fibrillary acidic protein (GFAP; a marker of astrocytes) and OX-42 (a marker of microglia) showed that 1 week following SCI, Cx43 was colocalized with GFAP, rather than OX-42, suggesting that resting (ramified) and reactive (rounded phagocytic) microglia rarely express Cx43 in the spinal cord.

In oligodendrocytes, Cx29, Cx32, and Cx47 are expressed in regions of the corticospinal tract and are localized to oligodendrocytic cell bodies as well as abaxonal membranes of myelinated fibers, and these three connexins have been shown to participate in astrocytic/oligodendritic gap junctions (Kleopa et al., 2004; Li etal., 2004; Kamasawa et al., 2005). In examining astrocytic/oligodendritic interfaces, Nagy etal. (2001) observed astrocytic Cx43 and Cx30 staining at apposed oligodendrocyte somata in wild type mice. When Cx32 in oligodendrotcyes was knocked out, Cx30 disappeared, while Cx43 levels remain active, furthering the notion of a $\mathrm{Cx} 43-\mathrm{Cx} 47$ and a Cx30-Cx32 heterotypic astrocytic/oligodendritic coupling (Nagy etal., 2001). Similarly, Kamasawa etal. (2005) showed that on the oligodendrocytic side, a greater abundance of Cx47 compared to Cx32 corresponded to a greater level of $\mathrm{Cx} 43$ on the astrocytic side, further supporting the notion of $\mathrm{Cx} 43-\mathrm{Cx} 47$ and $\mathrm{Cx} 30-\mathrm{Cx} 32$ heterotypic channels as being the major components of astrocytic/oligodendritic gap junctions.

The most likely role of coupling between glial cells is the creation of the glial syncytium, which amongst other processes such as the propagation of $\mathrm{Ca}^{2+}$ waves and transfer of metabolites, plays a crucial role in spatially buffering increases in extracellular $\mathrm{K}^{+}$. In the CNS, a low extracellular $\mathrm{K}^{+}$concentration is required for normal neuronal activity and thus pathological changes to connexin expressions are able to have a great impact on the balance of this system (Nagy and Rash, 2003; Rash, 2010). In addition, gap junction communication in glial cells is essential for normal central myelination. Indeed, mice deficient in both Cx32 and Cx47, which are expressed by oligodendrocytes, showed severe demyelinating phenotypes (Menichella et al., 2003; Odermatt et al., 2003). These double knockout mice developed gross tremors and tonic seizures, and died by the sixth postnatal week from profound abnormalities in central myelination. Abnormal changes included axons with thinly or absent myelinated sheaths, myelinated axons with markedly enlarged extracellular spaces separating the axon from its myelin sheath and occasional myelinated axons with enlarged collars of periaxonal oligodendrocyte cytoplasm (Menichella et al., 2003). 


\section{ROLE OF GAP JUNCTIONS IN SPINAL CORD INJURY}

Following a SCI, the initial impact leads to immediate hemorrhage and damage or disturbance to the neuronal elements of the spinal cord including severing of axon tracts and rapid cell death. The initial mechanical disruption is followed by multiple secondary cascades that cause further tissue loss and dysfunction. This secondary phase takes place during the first hours, days, or even months after the initial trauma. During this secondary phase, damage spreads to surrounding neuronal tissue, destroying gray and white matter in a process called the 'bystander' effect (Norenberg et al., 2004; Profyris et al., 2004). This encompasses glial cell responses such as astrogliosis and inflammatory cell activation, which can not only prevent neuronal repair, but also cause neuronal cell death. Cell death occurs via processes such as apoptosis, oxidative damage, and cytotoxic edema in astrocytes due to the buildup of glutamate and $\mathrm{K}^{+}$(Del Bigio and Johnson, 1989; Crowe et al., 1997; Springer et al., 1999; Norenberg et al., 2004; Fitch and Silver, 2008).

In terms of specific connexins, an early study showed that following a mechanically induced SCI in rodents, alterations in astrocytic $\mathrm{Cx} 43$ occurred in gray and white matter of the spinal cord (Theriault et al., 1997). Reactive astrocytes displaying GFAP appeared within 1 day and reached maximum levels at 3 days in the area of injury and areas that were both adjacent to and farther away from the lesion epicenter. The authors concluded that during their transformation to reactive states, spinal cord astrocytes experience altered $\mathrm{Cx} 43$ expression as a direct result of traumatic SCI (Theriault et al., 1997). These results were replicated by Lee et al. (2005), who used a model of transected adult spinal injury and in situ hybridization showing that astrocytic Cx43 protein and mRNA levels were largely increased $4 \mathrm{~h}$ after injury, while there were no changes in Cx32 or Cx36. After 4 weeks, levels of astrocytic $\mathrm{Cx} 43$ were three times higher in the caudal stump than the rostral stump, especially adjacent to the injury site, suggesting that increases in $\mathrm{Cx} 43$ are related to glial responses to injured tissue (Lee et al., 2005). Several studies that used selective inhibition of Cx43 channels in ex vivo and in vivo models of SCI have shown that $\mathrm{Cx} 43$ plays a role in the spread of injury and its blockage leads to improved recovery (Cronin et al., 2008; Zhang et al., 2010).

While increases in $\mathrm{Cx} 43$ protein have been widely reported following SCI, this does not appear to be the case with all connexins. Following up on reports that $\mathrm{Cx} 36$ mRNA was down regulated at the site of injury during the first week after SCI (Lee et al., 2005), Yates etal. (2008) observed that 7 days after a complete $\mathrm{T} 10$ transection in rats, $\mathrm{Cx} 36$ protein levels decreased in the lumbar enlargement distant to the site of injury in association with decreased electrical coupling. While this downregulation lasted 14 days post-injury, Cx36 returned to control levels over 2-4 weeks. This coincided with the onset of hyperreflexia and was normalized following oral administration of the eugeroic agent, Modafinil (Yates et al., 2008). The changes in neuronal gap junction protein Cx36 below the level of the lesion suggest that disruption to electrical coupling contributes to hyperreflexia and spasticity following SCI (Yates et al., 2011).

Recently, studies have shifted attention from gap junctional activity to the role of undocked hemichannels following SCI. While it was previously thought that these unopposed hemichannels occurred in closed states, recent evidence shows that contrastingly, hemichannels are able to open independent of channel docking, in a regulated manner during specialized physiological events as well as unregulated opening during pathological events (Contreras et al., 2004; Retamal et al., 2006, 2007). These hemichannels form large cell pores in the cell membrane which, upon opening, allow the exchange of ions and small molecules between intra and extracellular environments. It was found that in addition to playing a traditional role in gap junctions, hexamers of $\mathrm{Cx} 43$ are inserted at astroglial membranes as large pore single hemichannels that are able to mediate direct cytosolic exchange with the extracellular space (Giaume et al., 2013).

Of the small molecule substances released by opened undocked hemichannels following SCI, particular attention has been directed at ATP (Figure 1D). ATP release following increased hemichannel expression has been demonstrated both in vitro and in vivo. The application of an acidic fibroblast growth factor-1 (FGF-1) is able to activate spinal astrocytes in culture, causing increased levels of ATP and the opening of connexin channels, in particular, Cx43 (Garré et al., 2010). FGF-1 acts on the FGF receptor, and its activation causes increased levels of cytoplasmic $\mathrm{Ca}^{2+}$ and the release of ATP from vesicles through the activation of phospholipase C (Bennett et al., 2012). When a FGF-1 inhibitor was applied following a weight drop SCI, this caused reduced ATP levels, accompanied by a reduction in inflammatory cell recruitment and lesion expansion (Bennett et al., 2012). A recent study using $\mathrm{Cx} 43 \mathrm{KO}$ mice specific for astrocytes showed that there was a reduction in ATP-induced inflammation, decreased macrophage and microglial recruitment, and an increased functional recovery following SCI (Huang et al., 2012). This study followed past observations that rats subjected to cord contusion have abnormally high and sustained levels of ATP release. By using bioluminescence imaging, levels of ATP in peritraumatic zones were found to be significantly higher than the center of injury, and this elevated ATP release persisted for up to $6 \mathrm{~h}$ following SCI. In addition, secondary enlargement of the lesion occurred with signs of inflammation that included increased expression of GFAP, and recruitment of activated microglia and macrophages (Wang etal., 2004). The link between ATP signaling and $\mathrm{Cx} 43$ was further strengthened in a recent study by Chever et al. (2014). It was found that when hippocampal CA1 pyramidal slices were treated with Gap26, a Cx43 hemichannel blocking peptide, there was a fivefold decrease in extracellular ATP concentration. However, when the slices were pretreated with ATP P2 receptor antagonists, Gap26 failed to induce changes in ATP concentration suggesting that basal excitatory synaptic transmissions are regulated by astroglial $\mathrm{Cx} 43$ hemichannels through ATP signaling (Chever et al., 2014). While there is still a need for further research to elucidate the exact mechanisms, past studies have been able to provide a framework by which $\mathrm{Cx} 43$ hemichannels contribute to SCI. Following SCI, increased opening of astrocytic $\mathrm{Cx} 43$ channels causes the uncontrolled release of ATP into the perilesion region and inflammatory cell recruitment such as macrophage and microglia, which in turn causes the increased secondary expansion of the lesion. 


\section{ROLE OF GAP JUNCTIONS IN NEUROPATHIC PAIN FOLLOWING SPINAL CORD INJURY}

As many as $80 \%$ of SCI patients will suffer some form of chronic pain; nociceptive (e.g., musculoskeletal pain, visceral pain), neuropathic pain (at-level SCI pain, below-level SCI pain), or other pain (Finnerup and Baastrup, 2012). Neuropathic pain is the more debilitating and difficult to treat. It is important to note that neuropathic pain represents a series of heterogeneous conditions including various painful peripheral neuropathies (e.g., traumatic nerve injury, chemotherapy-induced peripheral neuropathy, postherpetic neuralgia) and central neuropathic pain, such as that occurring after SCI. However, despite the different etiologies and underlying mechanisms, the clinical manifestation of the pain is somewhat similar across the different neuropathic syndromes. Symptoms of both types of neuropathic pain include spontaneous pain presenting as burning, stinging, stabbing, or shooting sensations that is ongoing or intermittent; stimulus-evoked pain, which occurs in response to normally non-noxious (e.g., light touch) or noxious (e.g., cold, punctuate) stimuli; and abnormal sensations (e.g., paresthesia and dysesthesia). Neuropathic pain after SCI results from injury-induced neurochemical and neuroanatomical changes that contribute to maladaptive synaptic circuits and neuronal hyperexcitability in the spinal dorsal horn (Gwak and Hulsebosch, 2011). This pain has been reported as an important factor in decreased quality of life and has been shown to adversely impact function and daily routines in persons with SCI (Cairns et al., 1996; Siddall et al., 1999; Woolf and Mannion, 1999; Norenberg et al., 2004).

The conceptual basis of glial cells including astrocytes and microglia contributing to neuropathic pain is relatively new. The involvement of glial activation has been demonstrated in several chronic pain conditions, including inflammatory pain, peripheral, and central neuropathic pain (Wu et al., 2012). Activated glia can release ATP, excitatory amino acids, proinflammatory cytokines, and reactive oxygen species that in turn promote neuronal hyperexcitability in the dorsal horn of the spinal cord and contribute to neuropathic pain (Austin et al., 2012).

Glial activation has also been demonstrated in neuropathic pain following SCI (Hulsebosch et al., 2009). Several studies have demonstrated that rodents with SCI develop mechanical allodynia and thermal hyperalgesia, in association with astrocytic and microglial activation in segments that are uninjured and rostral to the initial injury site (Hains and Waxman, 2006; Peng et al., 2006; Carlton et al., 2009). Moreover, treatment with glial inhibitors, such as minocycline and propentofylline, reduced both mechanical allodynia and thermal hyperalgesia in the hind limbs of rats with below-level pain following SCI (Gwak et al., 2008; Gwak and Hulsebosch, 2009; Marchand et al., 2009).

Gap junctional activation via connexin channels has been proposed to play a role in glial cell activation, and thus neuropathic pain following SCI. Indeed, Roh et al. (2010) showed that in rats with T13 spinal cord hemisection the development of below-level neuropathic pain, including thermal hyperalgesia and mechanical allodynia, was attenuated following an intrathecal injection of carbenoxolone, a gap junction decoupler. In addition, daily treatment with carbenoxolone significantly reduced the SCI-induced increases in GFAP immunoreactivity and the phosphorylated
NMDA receptor NR1 immunoreactivity in the dorsal horn of the spinal cord. These effects were observed when carbenoxolone was administered during the induction phase (0-5 days after SCI), but not during the maintenance phase (15-20 days after SCI), when pain is already established (Roh et al., 2010). This suggests there is a critical time window in which a treatment to block astrocytic gap junctions could be effective in stopping the development of SCI pain.

A recent study using a targeted deletion approach has shown that $\mathrm{Cx} 43$ is linked to the development of neuropathic pain following acute SCI (Chen et al., 2012). After a weight drop SCI, control wild type and $\mathrm{Cx} 30$ deleted mice developed persistent neuropathic pain lasting from 4 to 8 weeks, which presented as heat hyperalgesia and mechanical allodynia in the presence of increased levels of GFAP positive cells. However, in $\mathrm{Cx} 43 / \mathrm{Cx} 30$ deleted mice, both the heat hyperalgesia and mechanical allodynia were prevented in addition to reduced levels of astrogliosis that continued up to 4 weeks. These findings indicate that Cx43 plays a significant role in the development of neuropathic pain following SCI.

\section{THERAPEUTIC APPLICATIONS}

During the past two decades, intercellular communication via gap junctions has provided a novel pharmacological target for treating SCI. The proposed mechanism of gap junction inhibitors is to induce a conformational change in the gap junction protein to control the intercellular and metabolic signaling cascades, such as ATP, glutamate, and reactive oxygen species (Takeuchi et al., 2006; Ramachandran et al., 2007; Clarke et al., 2009). Currently, there are a number of non-specific gap junction blockers such as carbenoxolone, and the antimalarial mefloquine that blocks Cx36 gap junctions at low concentrations ( $3 \mathrm{uM})$, while at higher concentrations (30 uM), completely inhibits Cx43 as well as Cx26 and Cx32 in neuroblastoma cells (Cruikshank et al., 2004). In addition, there are novel gap junction hemichannel blockers, such as INI-0602, which can penetrate the blood-brain barrier, and is a proven and effective treatment in mice models of neurodegenerative diseases (Takeuchi et al., 2011). It was recently shown that administration of INI-0602 in mice with SCI resulted in reduced glutamate excitotoxicity by inhibiting microglial activation. This subsequently promoted locomotor recovery and suppressed glial scar formation by reducing secondary degeneration. Further, INI-0602 treatment blocked neutrophil infiltration, stimulated increase in anti-inflammatory cytokines and elevated brain-derived neurotrophic factor levels (Umebayashi et al., 2014). Although such non-specific connexin blockers may be promising therapeutic strategies in SCI, a problem with these drugs is that it is very difficult to control their actions on specific hemichannels and thus establish effective regulation. For instance, a recent study has demonstrated that intrathecal injection of carbenoxolone up to 5 days post-hemisection SCI attenuated the induction of neuropathic pain and the astrogliosis at the lesion edge, but did not significantly improve hindlimb locomotor function (Roh et al., 2010). These global inhibitors non-specifically block all types of gap junctions, affecting physiological functions, such as thermoregulation and angiogenesis (Betageri and Rogers, 1987; Hong et al., 2009). While the global gap junction blockers have confining 
or questionable control of lesion spread and astrogliosis following traumatic CNS injury, other tissues containing connexin gap junctions may also be adversely affected.

A more targeted approach using antisense oligodeoxynucleotides (AS-ODN) and connexin mimetic peptides has been developed to prevent connexin signaling. Mimetic peptides are short peptides designed to mimic sequences on extracellular loops of connexin proteins. They prevent connexin hemichannel docking, thus blocking gap junctional intercellular communication (Warner et al., 1995; Kwak and Jongsma, 1999; Boitano and Evans, 2000; Martin et al., 2005). Although the mechanism of action for connexin mimetic peptides has not been fully elucidated, it has been proposed that they may induce a conformational change in connexin hemichannels via connexin phosphorylation, leading to the closure of the uncoupled hemichannels without blocking existing gap junctions (Chaytor et al., 1997). In cultured rodent spinal cords, when a Cx43-mimetic peptide, peptide 5, was given at doses between 5 and $500 \mu \mathrm{m}$ for $24 \mathrm{~h}$, swelling was reduced by $50 \%$ and neuronal loss was prevented. Furthermore, peptide 5 was able to reduce GFAP levels for up to 4 days in ex vivo spinal cord segments following SCI (O'Carroll et al., 2008). This was further supported by a study that used an AS-ODN to suppress Cx43 following a compression SCI in rodents, showing that treatment with $\mathrm{Cx} 43-\mathrm{ODN}$ resulted in less swelling, structural distortion and decreased GFAP positive cells in spinal cord segments (Cronin et al., 2008). In a follow-up study, peptide 5 administered after a spinal cord contusion injury in rats showed reduced levels of proinflammatory cytokines tumor necrosis factor (TNF)- $\alpha$ and interleukin (IL)-1 $\beta$, reduced GFAP staining in the area adjacent to the lesion epicenter, a reduction of neuronal loss $7 \mathrm{~mm}$ from the lesion epicenter as well as improved locomotor function (O'Carroll et al., 2013).

The application of connexin mimetic peptides has been widely studied in depressing immune responses (Neijssen et al., 2005; Matsue etal., 2006; Bopp etal., 2007), limiting cardiovascular damage (Wong etal., 2006; Shintani-Ishida et al., 2007), and inhibiting osteoclastic differentiation (Ilvesaro et al., 2001). Importantly, connexin mimetic peptides have the potential to be systemically delivered to target the lesion area of spinal cord in human patients, and offer a new hope to spinal cord-injured patients as an acute intervention. The regulation of $\mathrm{Cx} 43$ by AS-ODNs has been shown to not only protect neural cells after traumatic CNS injury, but also improve wound healing in many tissues, including cornea (Ratkay-Traub et al., 2001; Cursiefen et al., 2009; Grupcheva et al., 2012), skin (Coutinho et al., 2003; Qiu et al., 2003; Becker et al., 2012), skeletal muscle (Gorbe et al., 2006), cardiac muscle (Yasui et al., 2000), smooth muscle (Yeh et al., 1997; Liao and Duling, 2000), and vascular endothelium (Yeh et al., 2000; Kwak et al., 2001; Ormonde et al., 2012). Cx43 is upregulated at the wound edge of chronic wounds (Coutinho etal., 2003; Wang et al., 2007), and treatment with Cx43 ASODNs dampens the inflammatory response and decreases wound spread, resulting in reduced swelling and scarring and accelerated healing (Qiu et al., 2003; Coutinho et al., 2005; Mori et al., 2006). Significantly, several phase 1 or phase 2 clinical trials by CoDa Therapeutics, Inc. using the topical gel of Cx43 AS-ODNs (Nexagon ${ }^{\circledR}$ ) have shown the treatment to be safe and tolerable in skin wounds (NCT00736593), venous leg ulcers (NCT00820196 and NCT01199588), diabetic foot ulcer (NCT01490879), and acute corneal wounds (NCT00654550). Thus, based on animal studies and the clinical use of connexin inhibitors in various conditions, drugs that inhibit specific connexins, such as $\mathrm{Cx} 43$ AS-ODNs or Cx43 mimetic peptides, hold great promise for the treatment of SCI.

\section{ACKNOWLEDGMENTS}

This work was supported by a grant from the SCI Network "Toward Translation - Capacity Building Initiative" to Gila Moalem-Taylor, Catherine A. Gorrie, Colin R. Green, Simon J. O'Carroll, and Louise F. B. Nicholson.

\section{REFERENCES}

Altevogt, B. M., Kleopa, K. A., Postma, F. R., Scherer, S. S., and Paul, D. L. (2002). Connexin29 is uniquely distributed within myelinating glial cells of the central and peripheral nervous systems. J. Neurosci. 22, 6458-6470.

Altevogt, B. M., and Paul, D. L. (2004). Four classes of intercellular channels between glial cells in the CNS. J. Neurosci. 24, 4313-4323. doi: 10.1523/JNEUROSCI.330303.2004

Austin, P. J., Kim, C. F., Perera, C. J., and Moalem-Taylor, G. (2012). Regulatory $\mathrm{T}$ cells attenuate neuropathic pain following peripheral nerve injury and experimental autoimmune neuritis. Pain 153, 1916-1931. doi: 10.1016/j.pain.2012.0 6.005

Bautista, W., Mccrea, D., and Nagy, J. (2014). Connexin36 identified at morphologically mixed chemical/electrical synapses on trigeminal motoneurons and at primary afferent terminals on spinal cord neurons in adult mouse and rat. Neuroscience 236, 159-180. doi: 10.1016/j.neuroscience.2013.12.057

Becker, D. L., Thrasivoulou, C., and Phillips, A. R. (2012). Connexins in wound healing; perspectives in diabetic patients. Biochim. Biophys. Acta 1818, 2068-2075. doi: 10.1016/j.bbamem.2011.11.017

Bennett, M. V., Contreras, J. E., Bukauskas, F. F., and Sáez, J. C. (2003). New roles for astrocytes: gap junction hemichannels have something to communicate. Trends Neurosci. 26, 610-617. doi: 10.1016/j.tins.2003.09.008

Bennett, M. V., Garré, J. M., Orellana, J. A., Bukauskas, F. F., Nedergaard, M., Giaume, C., et al. (2012). Connexin and pannexin hemichannels in inflammatory responses of glia and neurons. Brain Res. 1487, 3-15. doi: 10.1016/j.brainres.2012.08.042

Betageri, G., and Rogers, J. (1987). Thermodynamics of partitioning of $\beta$-blockers in the n-octanol-buffer and liposome systems. Int. J. Pharm. 36, 165-173. doi: 10.1016/0378-5173(87)90152-9

Boitano, S., and Evans, W. H. (2000). Connexin mimetic peptides reversibly inhibit $\mathrm{Ca}^{2+}$ signaling through gap junctions in airway cells. Am. J. Physiol. Lung Cell. Mol. Physiol. 279, 623-630.

Bopp, T., Becker, C., Klein, M., Klein-Heßling, S., Palmetshofer, A., Serfling, E., et al. (2007). Cyclic adenosine monophosphate is a key component of regulatory T cellmediated suppression. J. Exp. Med. 204, 1303-1310. doi: 10.1084/jem.20062129

Buzsáki, G., and Chrobak, J. J. (1995). Temporal structure in spatially organized neuronal ensembles: a role for interneuronal networks. Curr. Opin. Neurobiol. 5, 504-510. doi: 10.1016/0959-4388(95)80012-3

Cairns, D. M., Adkins, R. H., and Scott, M. D. (1996). Pain and depression in acute traumatic spinal cord injury: origins of chronic problematic pain? Arch. Phys. Med. Rehabil. 77, 329-335. doi: 10.1016/S0003-9993(96)90079-9

Carlton, S. M., Du, J., Tan, H. Y., Nesic, O., Hargett, G. L., Bopp, A. C., et al. (2009). Peripheral and central sensitization in remote spinal cord regions contribute to central neuropathic pain after spinal cord injury. Pain 147, 265-276. doi: 10.1016/j.pain.2009.09.030

Chang, Q., and Balice-Gordon, R. J. (2000). Gap junctional communication among developing and injured motor neurons. Brain Res. Brain Res. Rev. 32, 242-249. doi: 10.1016/S0165-0173(99)00085-5

Chang, Q., Gonzalez, M., Pinter, M. J., and Balice-Gordon, R. J. (1999). Gap junctional coupling and patterns of connexin expression among neonatal rat lumbar spinal motor neurons. J. Neurosci. 19, 10813-10828.

Chaytor, A., Evans, W., Griffith, T., and Thornbury, K. (1997). Peptides homologous to extracellular loop motifs of connexin 43 reversibly abolish 
rhythmic contractile activity in rabbit arteries. J. Physiol. 503, 99-110. doi: 10.1111/j.1469-7793.1997.099bi.x

Chen, M. J., Kress, B., Han, X., Moll, K., Peng, W., Ji, R. R., et al. (2012). Astrocytic CX43 hemichannels and gap junctions play a crucial role in development of chronic neuropathic pain following spinal cord injury. Glia 60, 1660-1670. doi: 10.1002/glia.22384

Chever, O., Lee, C.-Y., and Rouach, N. (2014). Astroglial connexin43 hemichannels tune basal excitatory synaptic transmission. J. Neurosci. 34, 11228-11232. doi: 10.1523/JNEUROSCI.0015-14.2014

Clarke, T. C., Williams, O. J., Martin, P. E., and Evans, W. H. (2009). ATP release by cardiac myocytes in a simulated ischaemia model: inhibition by a connexin mimetic and enhancement by an antiarrhythmic peptide. Eur. J. Pharmacol. 605 9-14. doi: 10.1016/j.ejphar.2008.12.005

Contreras, J. E., Sáez, J. C., Bukauskas, F. F., and Bennett, M. V. (2003). Gating and regulation of connexin 43 (Cx43) hemichannels. Proc. Natl. Acad. Sci. U.S.A. 100 11388-11393. doi: 10.1073/pnas. 1434298100

Contreras, J. E., Sánchez, H. A., Eugenín, E. A., Speidel, D., Theis, M., Willecke, K. etal. (2002). Metabolic inhibition induces opening of unapposed connexin 43 gap junction hemichannels and reduces gap junctional communication in cortical astrocytes in culture. Proc. Natl. Acad. Sci. U.S.A. 99, 495-500. doi 10.1073/pnas.012589799

Contreras, J. E., Sánchez, H. A., Véliz, L. P., Bukauskas, F. F., Bennett, M. V., and Sáez, J. C. (2004). Role of connexin-based gap junction channels and hemichannels in ischemia-induced cell death in nervous tissue. Brain Res. Brain Res. Rev. 47 290-303. doi: 10.1016/j.brainresrev.2004.08.002

Coutinho, P., Qiu, C., Frank, S., Tamber, K., and Becker, D. (2003). Dynamic changes in connexin expression correlate with key events in the wound healing process. Cell Biol. Int. 27, 525-541. doi: 10.1016/S1065-6995(03)00077-5

Coutinho, P., Qiu, C., Frank, S., Wang, C., Brown, T., Green, C., et al. (2005). Limiting burn extension by transient inhibition of connexin43 expression at the site of injury. Br. J. Plast. Surg. 58, 658-667. doi: 10.1016/j.bjps.2004.1 2.022

Cronin, M., Anderson, P. N., Cook, J. E., Green, C. R., and Becker, D. L. (2008). Blocking connexin43 expression reduces inflammation and improves functional recovery after spinal cord injury. Mol. Cell. Neurosci. 39, 152-160. doi: 10.1016/i.mcn.2008.06.005

Crowe, M. J., Bresnahan, J. C., Shuman, S. L., Masters, J. N., and Crowe, M. S (1997). Apoptosis and delayed degeneration after spinal cord injury in rats and monkeys. Nat. Med. 3, 73-76. doi: 10.1038/nm0197-73

Cruikshank, S. J., Hopperstad, M., Younger, M., Connors, B. W., Spray, D. C., and Srinivas, M. (2004). Potent block of Cx36 and Cx50 gap junction channels by mefloquine. Proc. Natl. Acad. Sci. U.S.A. 101, 12364-12369. doi: 10.1073/pnas.0402044101

Cursiefen, C., Bock, F., Horn, F. K., Kruse, F. E., Seitz, B., Borderie, V., et al. (2009). GS-101 antisense oligonucleotide eye drops inhibit corneal neovascularization: interim results of a randomized phase II trial. Ophthalmology 116, 1630-1637. doi: 10.1016/j.ophtha.2009.04.016

Dahl, E., Manthey, D., Chen, Y., Schwarz, H.-J., Chang, Y. S., Lalley, P. A., et al (1996). Molecular cloning and functional expression of mouse connexin-30, a gap junction gene highly expressed in adult brain and skin. J. Biol. Chem. 271, 17903-17910. doi: 10.1074/jbc.271.30.17903

Del Bigio, M. R., and Johnson, G. E. (1989). Clinical presentation of spinal cord concussion. Spine 14, 37-40. doi: 10.1097/00007632-198901000-00007

Evans, W., De Vuyst, E., and Leybaert, L. (2006). The gap junction cellular internet: connexin hemichannels enter the signalling limelight. Biochem. J. 397, 1-14. doi: 10.1042/BJ20060175

Faustmann, P. M., Haase, C. G., Romberg, S., Hinkerohe, D., Szlachta, D. Smikalla, D., et al. (2003). Microglia activation influences dye coupling and Cx43 expression of the astrocytic network. Glia 42, 101-108. doi: 10.1002/glia.10141

Filippov, M. A., Hormuzdi, S. G., Fuchs, E. C., and Monyer, E. (2003). A reporter allele for investigating connexin 26 gene expression in the mouse brain. Eur. J. Neurosci. 18, 3183-3192. doi: 10.1111/j.1460-9568.2003.03042.x

Finnerup, N. B., and Baastrup, C. (2012). Spinal cord injury pain: mechanisms and management. Curr. Pain Headache Rep. 16, 207-216. doi: 10.1007/s11916-0120259-x

Fitch, M. T., and Silver, J. (2008). CNS injury, glial scars, and inflammation inhibitory extracellular matrices and regeneration failure. Exp. Neurol. 209, 294-301. doi: 10.1016/j.expneurol.2007.05.014
Fricker, D., and Miles, R. (2001). Interneurons, spike timing, and perception. Neuron 32, 771-774. doi: 10.1016/S0896-6273(01)00528-1

Garré, J. M., Retamal, M. A., Cassina, P., Barbeito, L., Bukauskas, F. F., Sáez, J. C., et al. (2010). FGF-1 induces ATP release from spinal astrocytes in culture and opens pannexin and connexin hemichannels. Proc. Natl. Acad. Sci. U.S.A. 107, 22659-22664. doi: 10.1073/pnas.1013793107

Giaume, C., Leybaert, L., Naus, C. C., and Sáez, J. C. (2013). Connexin and pannexin hemichannels in brain glial cells: properties, pharmacology, and roles. Front. Pharmacol. 4:88. doi: 10.3389/fphar.2013.00088

Gibson, J. R., Beierlein, M., and Connors, B. W. (2005). Functional properties of electrical synapses between inhibitory interneurons of neocortical layer 4 . J. Neurophysiol. 93, 467-480. doi: 10.1152/jn.00520.2004

Gorbe, A., Becker, D. L., Dux, L., Krenacs, L., and Krenacs, T. (2006). In differentiating prefusion myoblasts connexin43 gap junction coupling is upregulated before myoblast alignment then reduced in post-mitotic cells. Histochem. Cell Biol. 125, 705-716. doi: 10.1007/s00418-005-0121-x

Grupcheva, C. N., Laux, W. T., Rupenthal, I. D., Mcghee, J., Mcghee, C. N., and Green, C. R. (2012). Improved corneal wound healing through modulation of gap junction communication using connexin43-specific antisense oligodeoxynucleotides. Invest. Ophthalmol. Vis. Sci. 53, 1130-1138. doi: 10.1167/iovs.11-8711

Gwak, Y. S., Crown, E. D., Unabia, G. C., and Hulsebosch, C. E. (2008). Propentofylline attenuates allodynia, glial activation and modulates GABAergic tone after spinal cord injury in the rat. Pain 138, 410-422. doi: 10.1016/j.pain.2008.01.021

Gwak, Y. S., and Hulsebosch, C. E. (2009). Remote astrocytic and microglial activation modulates neuronal hyperexcitability and below-level neuropathic pain after spinal injury in rat. Neuroscience 161, 895-903. doi: 10.1016/j.neuroscience.2009.03.055

Gwak, Y. S., and Hulsebosch, C. E. (2011). Neuronal hyperexcitability: a substrate for central neuropathic pain after spinal cord injury. Curr. Pain Headache Rep. 15, 215-222. doi: 10.1007/s11916-011-0186-2

Haghikia, A., Ladage, K., Lafenetre, P., Haghikia, A., Hinkeroche, D., Smikalla, D., et al. (2008). Intracellular application of TNF-alpha impairs cell to cell communication via gap junctions in glioma cells. J. Neurooncol. 86, 143-152. doi: 10.1007/s11060-007-9462-8

Hains, B. C., and Waxman, S. G. (2006). Activated microglia contribute to the maintenance of chronic pain after spinal cord injury. J. Neurosci. 26, 4308-4317. doi: 10.1523/JNEUROSCI.0003-06.2006

Hertzberg, E. L., Lawrence, T. S., and Gilula, N. B. (1981). Gap junctional communication. Annu. Rev. Physiol. 43, 479-491. doi: 10.1146/annurev.ph.43. 030181.002403

Hinkerohe, D., Smikalla, D., Haghikia, A., Heupel, K., Haase, C. G., Dermietzel, R., et al. (2005). Effects of cytokines on microglial phenotypes and astroglial coupling in an inflammatory coculture model. Glia 52, 85-97. doi: 10.1002/glia. 20223

Hong, T., Wang, H., Wang, Y., and Wang, H. (2009). Effects of gap junctional blockers on cerebral vasospasm after subarachnoid hemorrhage in rabbits. Neurol. Res. 31, 238-244. doi: 10.1179/174313208X322770

Hormuzdi, S. G., Filippov, M. A., Mitropoulou, G., Monyer, H., and Bruzzone, R. (2004). Electrical synapses: a dynamic signaling system that shapes the activity of neuronal networks. Biochim. Biophys. Acta 1662, 113-137. doi: 10.1016/j.bbamem.2003.10.023

Huang, C., Han, X., Li, X., Lam, E., Peng, W., Lou, N., et al. (2012). Critical role of connexin 43 in secondary expansion of traumatic spinal cord injury. J. Neurosci. 32, 3333-3338. doi: 10.1523/JNEUROSCI.1216-11.2012

Hulsebosch, C. E., Hains, B. C., Crown, E. D., and Carlton, S. M. (2009). Mechanisms of chronic central neuropathic pain after spinal cord injury. Brain Res. Rev. 60, 202-213. doi: 10.1016/j.brainresrev.2008.12.010

Ilvesaro, J., Tavi, P., and Tukkanen, J. (2001). Connexin mimetic peptide Gap27 decreases osteoclastic activity. BMC Musculoskelet. Disord. 2:10. doi: 10.1186/1471-2474-2-10

Iyyathurai, J., D’hondt, C., Wang, N., De Bock, M., Himpens, B., Retamal, M. A., et al. (2013). Peptides and peptide derived molecules targetting the intracellular domains of Cx43: gap junctions versus hemichannels. Neuropharmacology 75, 491-505. doi: 10.1016/j.neuropharm.2013.04.050

Kamasawa, N., Sik, A., Morita, M., Yasumura, T., Davidson, K., Nagy, J., et al. (2005). Connexin-47 and connexin-32 in gap junctions of oligodendrocyte somata, myelin sheaths, paranodal loops and Schmidt-Lanterman incisures: implications 
for ionic homeostasis and potassium siphoning. Neuroscience 136, 65-86. doi: 10.1016/j.neuroscience.2005.08.027

Kiehn, O., Kjaerulff, O., Tresch, M. C., and Harris-Warrick, R. M. (2000). Contributions of intrinsic motor neuron properties to the production of rhythmic motor output in the mammalian spinal cord. Brain Res. Bull. 53, 649-659. doi: $10.1016 /$ S0361-9230(00)00398-1

Kiehn, O., and Tresch, M. C. (2002). Gap junctions and motor behavior. Trends Neurosci. 25, 108-115. doi: 10.1016/S0166-2236(02)02038-6

Kleopa, K. A., Orthmann, J. L., Enriquez, A., Paul, D. L., and Scherer, S. S. (2004). Unique distributions of the gap junction proteins connexin29, connexin32, and connexin47 in oligodendrocytes. Glia 47, 346-357. doi: 10.1002/glia.20043

Kunzelmann, P., Schröder, W., Traub, O., Steinhäuser, C., Dermietzel, R., and Willecke, K. (1999). Late onset and increasing expression of the gap junction protein connexin 30 in adult murine brain and long-term cultured astrocytes. Glia 25, 111-119. doi: 10.1002/(SICI)1098-1136(19990115)25:2<111::AIDGLIA2>3.0.CO;2-I

Kwak, B. R., and Jongsma, H. J. (1999). Selective inhibition of gap junction channel activity by synthetic peptides. J. Physiol. 516, 679-685. doi: 10.1111/j.1469-7793.1999.0679u.x

Kwak, B. R., Pepper, M. S., Gros, D. B., and Meda, P. (2001). Inhibition of endothelial wound repair by dominant negative connexin inhibitors. Mol. Biol. Cell 12, 831845. doi: $10.1091 / \mathrm{mbc} .12 .4 .831$

Lampe, P. D., and Lau, A. F. (2000). Regulation of gap junctions by phosphorylation of connexins. Arch. Biochem. Biophys. 384, 205-215. doi: 10.1006/abbi.2000.2131

Lee, I. H., Lindqvist, E., Kiehn, O., Widenfalk, J., and Olson, L. (2005). Glial and neuronal connexin expression patterns in the rat spinal cord during development and following injury. J. Comp. Neurol. 489, 1-10. doi: 10.1002/cne.20567

Li, X., Ionescu, A., Lynn, B., Lu, S., Kamasawa, N., Morita, M., et al. (2004) Connexin47, connexin29 and connexin32 co-expression in oligodendrocytes and Cx47 association with zonula occludens-1 (ZO-1) in mouse brain. Neuroscience 126, 611-630. doi: 10.1016/j.neuroscience.2004.03.063

Liao, Y., and Duling, B. R. (2000). Blockade of connexin 43 expression by stable transfection of antisense cDNA in cultured vascular smooth muscle cells. Antisense Nucleic Acid Drug Dev. 10, 275-281. doi: 10.1089/108729000421457

Marchand, F., Tsantoulas, C., Singh, D., Grist, J., Clark, A. K., Bradbury, E. J., et al. (2009). Effects of etanercept and minocycline in a rat model of spinal cord injury. Eur. J. Pain 13, 673-681. doi: 10.1016/j.ejpain.2008.08.001

Martin, P. E., Wall, C., and Griffith, T. M. (2005). Effects of connexin-mimetic peptides on gap junction functionality and connexin expression in cultured vascular cells. Br. J. Pharmacol. 144, 617-627. doi: 10.1038/sj.bjp.0706102

Matsue, H., Yao, J., Matsue, K., Nagasaka, A., Sugiyama, H., Aoki, R., et al. (2006). Gap junction-mediated intercellular communication between dendritic cells (DCs) is required for effective activation of DCs. J. Immunol. 176, 181-190. doi: 10.4049/jimmunol.176.1.181

Menichella, D. M., Goodenough, D. A., Sirkowski, E., Scherer, S. S., and Paul, D. L. (2003). Connexins are critical for normal myelination in the CNS. J. Neurosci. 23, 5963-5973.

Meyer, A., Hilgen, G., Dorgau, B., Sammler, E. M., Weiler, R., Monyer, H., et al. (2014). All amacrine cells discriminate between heterocellular and homocellular locations when assembling connexin36 containing gap junctions. J. Cell Sci. 127, 1190-1202. doi: 10.1242/jcs.133066

Mori, R., Power, K. T., Wang, C. M., Martin, P., and Becker, D. L. (2006). Acute downregulation of connexin 43 at wound sites leads to a reduced inflammatory response, enhanced keratinocyte proliferation and wound fibroblast migration. J. Cell Sci. 119, 5193-5203. doi: 10.1242/jcs.03320

Nagy, J. I., Li, X., Rempel, J., Stelmack, G., Patel, D., Staines, W. A., et al. (2001). Connexin26 in adult rodent central nervous system: demonstration at astrocytic gap junctions and colocalization with connexin30 and connexin43. J. Comp. Neurol. 441, 302-323. doi: 10.1002/cne.1414

Nagy, J. I., and Rash, J. E. (2003). Astrocyte and oligodendrocyte connexins of the glial syncytium in relation to astrocyte anatomical domains and spatial buffering. Cell Commun. Adhes. 10, 401-406. doi: 10.1080/cac.10.4-6.401.406

Neijssen, J., Herberts, C., Drijfhout, J. W., Reits, E., Janssen, L., and Neefjes, J. (2005). Cross-presentation by intercellular peptide transfer through gap junctions. Nature 434, 83-88. doi: 10.1038/nature03290

Norenberg, M. D., Smith, J., and Marcillo, A. (2004). The pathology of human spinal cord injury: defining the problems. J. Neurotrauma 21, 429-440. doi: $10.1089 / 089771504323004575$
O'Carroll, S. J., Alkadhi, M., Nicholson, L. F., and Green, C. R. (2008). Connexin43 mimetic peptides reduce swelling, astrogliosis, and neuronal cell death after spinal cord injury. Cell Commun. Adhes. 15, 27-42. doi: 10.1080/154190608020 14164

O'Carroll, S. J., Gorrie, C. A., Velamoor, S., Green, C. R., and Nicholson, L. F. (2013). Connexin 43 mimetic peptide is neuroprotective and improves function following spinal cord injury. Neurosci. Res. 75, 256-267. doi: 10.1016/j.neures.2013.01.004

Odermatt, B., Wellershaus, K., Wallraff, A., Seifert, G., Degen, J., Euwens, C., et al. (2003). Connexin 47 (Cx47)-deficient mice with enhanced green fluorescent protein reporter gene reveal predominant oligodendrocytic expression of $\mathrm{Cx} 47$ and display vacuolized myelin in the CNS. J. Neurosci. 23, 4549-4559.

Ormonde, S., Chou, C.-Y., Goold, L., Petsoglou, C., Al-Taie, R., Sherwin, T., et al. (2012). Regulation of connexin 43 gap junction protein triggers vascular recovery and healing in human ocular persistent epithelial defect wounds. J. Membr. Biol. 245, 381-388. doi: 10.1007/s00232-012-9460-4

Orthmann-Murphy, J. L., Abrams, C. K., and Scherer, S. S. (2008). Gap junctions couple astrocytes and oligodendrocytes. J. Mol. Neurosci. 35, 101-116. doi: 10.1007/s12031-007-9027-5

Pannasch, U., Vargová, L., Reingruber, J., Ezan, P., Holcman, D., Giaume, C., et al. (2011). Astroglial networks scale synaptic activity and plasticity. Proc. Natl. Acad. Sci. U.S.A. 108, 8467-8472. doi: 10.1073/pnas. 1016650108

Peng, X. M., Zhou, Z. G., Glorioso, J. C., Fink, D. J., and Mata, M. (2006). Tumor necrosis factor- $\alpha$ contributes to below-level neuropathic pain after spinal cord injury. Ann. Neurol. 59, 843-851. doi: 10.1002/ana.20855

Profyris, C., Cheema, S. S., Zang, D., Azari, M. F., Boyle, K., and Petratos, S. (2004). Degenerative and regenerative mechanisms governing spinal cord injury. Neurobiol. Dis. 15, 415-436. doi: 10.1016/j.nbd.2003.11.015

Qiu, C., Coutinho, P., Frank, S., Franke, S., Law, L.-Y., Martin, P., et al. (2003). Targeting connexin43 expression accelerates the rate of wound repair. Curr. Biol. 13, 1697-1703. doi: 10.1016/j.cub.2003.09.007

Ramachandran, S., Xie, L.-H., John, S. A., Subramaniam, S., and Lal, R. (2007). A novel role for connexin hemichannel in oxidative stress and smoking-induced cell injury. PLoS ONE 2:e712. doi: 10.1371/journal.pone.0000712

Rash, J., Staines, W., Yasumura, T., Patel, D., Furman, C., Stelmack, G., et al. (2000). Immunogold evidence that neuronal gap junctions in adult rat brain and spinal cord contain connexin-36 but not connexin-32 or connexin-43. Proc. Natl. Acad. Sci. U.S.A. 97, 7573-7578. doi: 10.1073/pnas.97.13.7573

Rash, J. E. (2010). Molecular disruptions of the panglial syncytium block potassium siphoning and axonal saltatory conduction: pertinence to neuromyelitis optica and other demyelinating diseases of the central nervous system. Neuroscience 168, 982-1008. doi: 10.1016/j.neuroscience.2009.10.028

Ratkay-Traub, I., Hopp, B., Bor, Z., Dux, L., Becker, D., and Krenacs, T. (2001). Regeneration of rabbit cornea following excimer laser photorefractive keratectomy: a study on gap junctions, epithelial junctions and epidermal growth factor receptor expression in correlation with cell proliferation. Exp. Eye Res. 73, 291-302. doi: 10.1006/exer.2001.1040

Retamal, M. A., Cortés, C. J., Reuss, L., Bennett, M. V., and Sáez, J. C. (2006). S-nitrosylation and permeation through connexin 43 hemichannels in astrocytes: induction by oxidant stress and reversal by reducing agents. Proc. Natl. Acad. Sci. U.S.A. 103, 4475-4480. doi: 10.1073/pnas.0511118103

Retamal, M. A., Schalper, K. A., Shoji, K. F., Bennett, M. V., and Sáez, J. C. (2007). Opening of connexin 43 hemichannels is increased by lowering intracellular redox potential. Proc. Natl. Acad. Sci. U.S.A. 104, 8322-8327. doi: 10.1073/pnas.0702456104

Roh, D. H., Yoon, S. Y., Seo, H. S., Kang, S. Y., Han, H. J., Beitz, A. J., et al. (2010). Intrathecal injection of carbenoxolone, a gap junction decoupler, attenuates the induction of below-level neuropathic pain after spinal cord injury in rats. Exp. Neurol. 224, 123-132. doi: 10.1016/j.expneurol.2010.03.002

Shintani-Ishida, K., Uemura, K., and Yoshida, K.-I. (2007). Hemichannels in cardiomyocytes open transiently during ischemia and contribute to reperfusion injury following brief ischemia. Am. J. Physiol. Heart Circ. Physiol. 293, 1714-1720. doi: 10.1152/ajpheart.00022.2007

Siddall, P. J., Taylor, D. A., Mcclelland, J. M., Rutkowski, S. B., and Cousins, M. J. (1999). Pain report and the relationship of pain to physical factors in the first 6 months following spinal cord injury. Pain 81, 187-197. doi: 10.1016/S03043959(99)00023-8

Söhl, G., Maxeiner, S., and Willecke, K. (2005). Expression and functions of neuronal gap junctions. Nat. Rev. Neurosci. 6, 191-200. doi: 10.1038/nrn1627 
Söhl, G., and Willecke, K. (2003). An update on connexin genes and their nomenclature in mouse and man. Cell Commun. Adhes. 10, 173-180. doi: 10.1080/cac.10.4-6.173.180

Springer, J. E., Azbill, R. D., and Knapp, P. E. (1999). Activation of the caspase-3 apoptotic cascade in traumatic spinal cord injury. Nat. Med. 5, 943-946. doi: $10.1038 / 11387$

Stehberg, J., Moraga-Amaro, R., Salazar, C., Becerra, A., Echeverría, C., Orellana, J. A., et al. (2012). Release of gliotransmitters through astroglial connexin 43 hemichannels is necessary for fear memory consolidation in the basolateral amygdala. FASEB J. 26, 3649-3657. doi: 10.1096/fj.11-198416

Takeuchi, H., Jin, S., Wang, J., Zhang, G., Kawanokuchi, J., Kuno, R., et al. (2006). Tumor necrosis factor- $\alpha$ induces neurotoxicity via glutamate release from hemichannels of activated microglia in an autocrine manner. J. Biol. Chem. 281, 21362-21368. doi: 10.1074/jbc.M600504200

Takeuchi, H., Mizoguchi, H., Doi, Y., Jin, S., Noda, M., Liang, J., et al. (2011). Blockade of gap junction hemichannel suppressess disease progression in mouse models of amyotrophic lateral sclerosis and Alzheimers disease. PLoS ONE 6:e21108. doi: 10.1371/journal.pone.0021108

Theriault, E., Frankenstein, U., Hertzberg, E., and Nagy, J. (1997). Connexin43 and astrocytic gap junctions in the rat spinal cord after acute compression injury. J. Comp. Neurol. 382, 199-214. doi: 10.1002/(SICI)10969861(19970602)382:2<199::AID-CNE5>3.0.CO;2-Z

Umebayashi, D., Natsume, A., Takeuchi, H., Hara, M., Nishimura, Y., Fukuyama, R., et al. (2014). Blockade of gap junction hemichannels protects secondary spinal cord injury from activated microglia mediated glutamate exitoneurotoxicity. J. Neurotrauma 21, 1-8. doi: 10.1089/neu.2013.3223

Wang, C. M., Lincoln, J., Cook, J. E., and Becker, D. L. (2007). Abnormal connexin expression underlies delayed wound healing in diabetic skin. Diabetes 56, 2809 2817. doi: 10.2337/db07-0613

Wang, X., Arcuino, G., Takano, T., Lin, J., Peng, W. G., Wan, P., et al. (2004). P2X7 receptor inhibition improves recovery after spinal cord injury. Nat. Med. 10, 821-827. doi: 10.1038/nm1082

Warner, A., Clements, D., Parikh, S., Evans, W., and Dehaan, R. (1995). Specific motifs in the external loops of connexin proteins can determine gap junction formation between chick heart myocytes. J. Physiol. 488, 721-728.

Wilson, J. M., Cowan, A. I., and Brownstone, R. M. (2007). Heterogeneous electrotonic coupling and synchronization of rhythmic bursting activity in mouse Hb9 interneurons. J. Neurophysiol. 98, 2370-2381. doi: 10.1152/jn.0033 8.2007

Wong, C. W., Christen, T., Roth, I., Chadjichristos, C. E., Derouette, J.-P., Foglia, B. F., et al. (2006). Connexin37 protects against atherosclerosis by regulating monocyte adhesion. Nat. Med. 12, 950-954. doi: 10.1038/nm1441
Woolf, C. J., and Mannion, R. J. (1999). Neuropathic pain: aetiology, symptoms, mechanisms, and management. Lancet 353, 1959-1964. doi: 10.1016/S01406736(99)01307-0

Wu, A., Green, C. R., Rupenthal, I. D., and Moalem-Taylor, G. (2012). Role of gap junctions in chronic pain. J. Neurosci. Res. 90, 337-345. doi: 10.1002/jnr.22764

Yasui, K., Kada, K., Hojo, M., Lee, J.-K., Kamiya, K., Toyama, J., et al. (2000). Cell-tocell interaction prevents cell death in cultured neonatal rat ventricular myocytes. Cardiovasc. Res. 48, 68-76. doi: 10.1016/S0008-6363(00)00145-0

Yates, C., Charlesworth, A., Allen, S., Reese, N., Skinner, R., and Garcia-Rill, E. (2008). The onset of hyperreflexia in the rat following complete spinal cord transection. Spinal Cord 46, 798-803. doi: 10.1038/sc.2008.49

Yates, C., Garrison, K., Reese, N. B., Charlesworth, A., and Garcia-Rill, E. (2011). Chapter 11-Novel mechanism for hyperreflexia and spasticity. Prog. Brain Res. 188, 167-180. doi: 10.1016/B978-0-444-53825-3.00016-4

Yeh, H. I., Lai, Y. J., Chang, H. M., Ko, Y. S., Severs, N. J., and Tsai, C. H. (2000). Multiple connexin expression in regenerating arterial endothelial gap junctions. Arterioscler. Thromb. Vasc. Biol. 20, 1753-1762. doi: 10.1161/01.ATV.20.7.1753

Yeh, H. I., Lupu, F., Dupont, E., and Severs, N. J. (1997). Upregulation of connexin43 gap junctions between smooth muscle cells after balloon catheter injury in the rat carotid artery. Arterioscler. Thromb. Vasc. Biol. 17, 3174-3184. doi: 10.1161/01.ATV.17.11.3174

Zhang, J., O’Carroll, S. J., Wu, A., Nicholson, L. F. B., and Green, C. R. (2010). A model for ex vivo spinal cord segment culture - a tool for analysis of injury repair strategies. J. Neurosci. Methods 192, 49-57. doi: 10.1016/j.jneumeth.2010.07.012

Conflict of Interest Statement: The authors declare that the research was conducted in the absence of any commercial or financial relationships that could be construed as a potential conflict of interest.

Received: 08 October 2014; accepted: 12 December 2014; published online: 06 January 2015.

Citation: Tonkin RS, Mao Y, O'Carroll SJ, Nicholson LFB, Green CR, Gorrie CA and Moalem-Taylor $G$ (2015) Gap junction proteins and their role in spinal cord injury. Front. Mol. Neurosci. 7:102. doi: 10.3389/fnmol.2014.00102

This article was submitted to the journal Frontiers in Molecular Neuroscience.

Copyright (C) 2015 Tonkin, Mao, O'Carroll, Nicholson, Green, Gorrie and MoalemTaylor. This is an open-access article distributed under the terms of the Creative Commons Attribution License (CC BY). The use, distribution or reproduction in other forums is permitted, provided the original author(s) or licensor are credited and that the original publication in this journal is cited, in accordance with accepted academic practice. No use, distribution or reproduction is permitted which does not comply with these terms. 